\title{
Clarification Regarding Generic Substitution for Psychotropic Drugs
}

\section{To the Editor:}

Please be advised that there is an error in the article, "Generic Substitutions for Psychotropic Drugs," which appeared in the September 2009 Supplement to CNS Spectrums, Volume 14, Number 9. In several places in the article, statements indicate that a generic formulation is available for escitalopram, and provides a generic availability date of 2006. These statements are incorrect. In fact, at this time, no generic formulation is commercially available for Lexapro (escitalopram) in the United States. Forest Laboratories retains patent/exclusivity for Lexapro until March $2012 .^{1}$

These statements appear on the following pages: Focus Points section (page 1), the text of the response to question 1 (pages 2-3) and the Table (page 3). The corrected text for these statements is provided below:

- On page 1, Focus Points section, bullet 1, the corrected statement should read: "Many psychotropic agents currently in use are available as generic products-including citalopram, fluoxetine, paroxetine, sertraline, and venlafaxine."

- On page 2, column 2, paragraph 4, lines 5-7, continuing on page 3 , column 1 , paragraph 1 , lines 1-2, the corrected statement should read: "With the exception of escitalopram, for which no generic formulation is currently available in the US, each of the selective serotonin reuptake inhibitors is off-patent and is available as a generic product, including fluoxetine (since 2001), paroxetine (since 2003), citalopram (since 2004), and sertraline (since 2006). ${ }^{1,17 "}$

- On page 3, the Table, "Antidepressants and Antipsychotics," line 2 under the category SSRIs, the corrected text for the Generic Approval of Lexapro (escitalopram) should read: "N/A" (for not applicable).

Finally, in an effort to avoid future disparities between the dates provided for generic approval in this Supplement and the dates when the generic formulation becomes commercially available, the Table (see page 710) has been updated to provide generic approval dates only for those cases in which a generic formulation currently is available. For drugs for which no generic currently is available, the table simply states "N/A" for not applicable.

Sincerely,

Pierre Blier, MD, PhD

\section{REFERENCE}

1. Food and Drug Administration Electronic Orange Book. Approved Drug Products With Therapeutic Equivalence Evaluations. Patent and Exclusivity Search Results from query on Appl No 021323 Product 001 in the OB_Rx list. Available at: www.accessdata.fda.gov/scripts/cder/ob/docs/patexc/new.cfm?Appl_No=021323\&Product_ No $=001$ \&table1 $=0 B \_$Rx. Accessed November 19, 2009 .

Dr. Blier is endowed chair and director of Mood Disorders Research and professor in the Department of Psychiatry and Cellular/Molecular Medicines at the University of Ottawa Institute of Mental Health Research in Canada.

Faculty Disclosures: Dr. Blier is a consultant to AstraZeneca, Biovail, Bristol-Myers Squibb, Eli Lilly, Janssen, Lundbeck, Novartis, Pfizer, sanofi-aventis, Schering-Plough, Sepracor, Servier, Takeda, and Wyeth; is on the speaker's bureau of Janssen, Lundbeck, and Wyeth; receives grant support from Bristol-Myers Squibb, Cyberonics, Janssen, Labopharm, Lundbeck, Mitsubishi Pharma, Schering-Plough, Sepracor, Servier, and Wyeth; and has a financial interest in Medical Multimedia Inc. and Steelbeach Productions.

Submitted for publication: November 24, 2009; Accepted for publication: November 24, 2009. 


\section{TABLE}

Antidepressants and Antipsychotics'

Brand (Generic)
SSRIs
Celexa (citalopram)
Lexapro (escitalopram)
Paxil (paroxetine) IR
Paxil (paroxetine) CR
Prozac (fluoxetine)
Zoloft (sertraline)

\section{SNRIS}

Effexor (venlafaxine) IR Effexor (venlafaxine) XR Cymbalta (duloxetine) Pristiq (desvenlafaxine)

\section{Other Antidepressants}

Remeron (mirtazapine) Remeron (mirtazapine) ODT Wellbutrin (bupropion) IR Wellbutrin (bupropion) SR Wellbutrin (bupropion) XL

\section{Atypical Antipsychotics}

Abilify (aripiprazole) Abilify (aripiprazole) ODT Clozaril (clozapine) Fazaclo (clozapine) ODT Geodon (ziprasidone) Invega (paliperidone) Risperdal (risperidone) Risperdal (risperidone) ODT Saphris (asenapine) Seroquel (quetiapine) Seroquel (quetiapine) XR Zyprexa (olanzapine) Zyprexa (olanzapine) Zydis

\section{Generic Approval*}

July 1998
August 2002
December 1992
February 1999
December 1987
December 1991

\author{
October 2004 \\ N/A \\ July 2003 \\ June 2007 \\ August 2001 \\ June 2006
}

* Earliest date of generic approval by the US FDA is listed for compounds for which a generic is commercially available; N/A is stated for brands for which no generic is commercially available.

† The US FDA approved a generic venlafaxine extended-release tablet that is bioequivalent but not therapeutically equivalent, and therefore not routinely substitutable for Effexor XR.

SSRIs=selective serotonin reuptake inhibitors; IR=immediate release; $C R=$ controlled release; SNRIS=serotonin norepinephrine reuptake inhibitors; $X R=$ extended release; $\mathrm{NCE}=$ new chemical entity; $\mathrm{ODT}=0$ rally disintegrating tablet; $\mathrm{SR}=$ sustained release; $\mathrm{XL}=$ extended release; $N / A=$ not applicable; $N D F=$ new dosage formulation. 